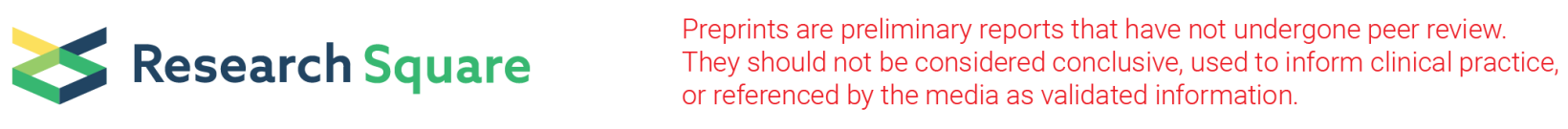

\title{
Factors affecting community based health insurance utilization in Ethiopia: A systematic review
}

\author{
Ewunetie Mekashaw Bayked ( $\square$ mekashawe@gmail.com ) \\ Wollo University https://orcid.org/0000-0002-8060-3922 \\ Mesfin Haile Kahissay \\ University of Wollongong Faculty of Engineering and Information Sciences \\ Birhanu Demeke Workneh \\ Wollo University
}

\section{Research article}

Keywords: Determinants, Factors, Health insurance, Community based health insurance, Willingness to utilize, Willingness to join, Willingness to pay, Willingness to uptake, Willingness to enroll and Ethiopia

Posted Date: December 2nd, 2019

DOI: https://doi.org/10.21203/rs.2.17949/v1

License: (c) (i) This work is licensed under a Creative Commons Attribution 4.0 International License. Read Full License 


\section{Abstract}

Background: The goal of health care financing in Ethiopia has been to achieve universal health care coverage by minimizing the catastrophic out of pocket health service expenditure. Even though the performance was not as planned, the promising strategy to achieve universal health care coverage in the informal sector was community based health insurance which was expected to cover more than $83 \%$ of the population. So, we systematically reviewed determinants of community based health insurance utilization in Ethiopia.

Methods: We searched DOAJ, EconBiz, ERIC, Google Scholar, Oxford Journals, PubMed, SpringerLink, Europe PMC, Microsoft Academic Search, OAlster and AJ including various relevant websites by March 9 to 10, 2019. We included articles regardless of their publication status with both quantitative and qualitative approaches.

Results: The factors determining community based health insurance utilization in Ethiopia were found to be associated with supply side, health facility, demographic and socioeconomic predictors. Among demographic and socio-economic factors, the report of the studies regarding to gender and age was not consistent. However income, education, community participation, marriage, occupation and family size were found to be significant predictors and were positively related with the scheme's utilization. With respect to health status and health service related factors; illness experience, benefit package, awareness level, previous out of pocket expenditure for health care service and health service status (quality, adequacy, efficiency and coverage) were significantly and positively related but premium amount, self-rated health status and bureaucratic complexity were found to be negative predictors.

Conclusion: To achieve universal health care coverage through community based health insurance, it is advisable that special attention should be given to income level, education, community participation, marriage, family size, benefit package, awareness level and health service quality, premium amount and bureaucratic or governance issue.

\section{Background}

Since 1993, various reforms in the health sector have been undertaken in Ethiopia [1-3] envisioned at health care financing strategy [3, 4] aimed to identify resource alternatives to ensure universal health coverage (UHC) $[2,5,6]$. However, health care service of the country is among the worst not only in the world [7] but also in Sub Saharan Africa (SSA) especially in children, women, and the elderly [1-3, 7]. Shortage of finance is the "single most" important pathogen negatively affecting the health care service [7]. However, the catastrophic out of pocket (OOP) expenditure [8, 9] continues to be the main alternative of financing health care in Ethiopia [9]. Thus, Ethiopian government has been devoted to find a way to shift from catastrophic OOP expenditure $[10,11]$ to ensure accessibility $[11,12]$ targeting on quality and equity $[5,6]$ to achieve UHC $[12,13]$. As a result, health insurance has been taken as a strategy in 2008 [6] with two schemes (risk-pooling arrangements) called social health insurance for the formal sector and community-based health insurance $(\mathrm{CBHI})$ for the informal sector $[4,13,14]$ to cover all citizens with the exception of defense forces [13]. But, the mandatory social health insurance was' not still implemented [15] even if it was expected to be launched in 2014 [16].

$\mathrm{CBH}$ is a non-compulsory and non-profit making risk pooling mechanism in exchange for premium payments by members aimed to address the issue of UHC by limiting financial hardship [17-20]. CBHI is among contemporary alternatives to address the issue of equity in health service provision [7,

20]. Though the issue of $\mathrm{CBHI}$ is assumed to be new, the risk sharing practice of Ethiopians is not new. Iddir, indigenous community based insurance, is being practiced at the time of financial hardship. It is based on mutual understanding and motivation [21-23] and is accepted and sustainable alternative to user fees to protect against impoverishment at the time of critical health events [24]. Likewise, CBHI is based on autonomous decision [15]. If CBHI is not in place, households face catastrophic OOP expense through borrowing to cover direct and indirect health care costs. For those who are unable to get money, it is unthinkable to take health care [25]. Hence, with no any risk pooling mechanism, households face impoverishment from OOP expense [26]. By avoiding OOP payment, CBHI can improve access, overall quality of service and health care utilization [27, 28].

CBHI was introduced [18] and launched in Ethiopia in 2011 [29, 30] and was begun to be implemented in 2011 in 13 districts of four most populous regions (Amhara, Tigray, Oromia and Southern nations nationalities and peoples (SNNP) [2, 29, 31, 32]. The aim was to decrease 00P expenditure that hampers accessibility to health care [29]. The overall enrollment in these Woredas was more than half (52\%) of the expected population by 2013 [2]. Even though, healthcare utilization was found to be higher among insured households than uninsured [11], the achievement of CBHI by $2015 / 2016$ was far away from the expected [15]. In contrast to financial limitation [21]; OOP health expenditure is still high (38.5\%) [15]. Consequently, the accessibility, equity, equality and quality of health service in Ethiopia is at the bottom of its path [7, 20]. As a result, access of the community to health service is still very low [15]. Thus, our objective was to systematically review factors affecting community based health insurance utilization in Ethiopia.

\section{Methods}

\section{Protocol and registration}

This review was based on systematic review protocol of "factors that affect the uptake of community-based health insurance in low-income and middle-income countries" [33]. 


\section{Search strategy}

We intensively searched these databases: Directory of Open Access Journals (DOAJ), Journals, Working Papers \& Conferences in Business Studies and Economics (EconBiz), Education Resources Information Center (ERIC), Google Scholar, Oxford Journals, PubMed, SpringerLink, Europe PMC, Microsoft Academic Search, OAlster and Academic Journals (AJ) with no consideration in publication status. For PubMed, the resources were searched by using medical subject headings (MeSH) and text words in line with the objective of the review: "Factors" or "Determinants" or "Willingness to join" or "Willingness to pay" or "Willingness to uptake" or "Willingness to enroll", "Willingness to utilize" or "Community based health insurance" or "Health insurance" and "Ethiopia". We also searched various websites like Ethiopian Health Insurance Agency (EHIA) (http://ehia.gov.et/), African Studies Center (ASC) (https://www.ascleiden.nl/), United States Agency for International Development (USAID) (http://www.usaid.gov/), the Ethiopian Herald (http://www.ethpress.gov.et/herald/), Ethiopian Federal Ministry of Health (EFMOH) (http://www.moh.gov.et/), Addis Ababa University (AAU) (http://www.aau.edu.et/), American Public Health Association (APHA) (http://www.apha.org/) and World Health Organization (WHO) (https://www.who.int/).

\section{Study selection}

The literatures were screened by two independent reviewers (EMB and MHK). Firstly, the articles were refined by their title and abstract; secondly, by full text revision by these Authors independently and finally together.

\section{Eligibility criteria}

Any study that reported factors affecting $\mathrm{CBHI}$ was included with both qualitative and quantitative approach. For this article, $\mathrm{CBHI}$ is redefined as a non-compulsory and non-profit making risk pooling mechanism in exchange for premium payments by members aimed to address the issue of UHC by limiting financial hardship and is based on the community's traditional risk sharing arrangements. Iddir based health insurance is thus taken as a synonym for $\mathrm{CBHI}$. The included articles were those that had reported the willingness to participate, join, pay, uptake, enroll and utilize $\mathrm{CBHI}$ as the priority finding; and health care utilization, attitude to $\mathrm{CBHI}$, availability of health service and medical equipment, satisfaction with $\mathrm{CBH}$, dropout rate from $\mathrm{CBHI}$ and $\mathrm{CBHI}$ membership renewal as additional outcome.

\section{Risk of bias assessment}

Risk of bias for individual studies was assessed by developing a modified assessment tool in a scale of measurement from "Strengthening the reporting of observational studies in epidemiology (STROBE) statement: guidelines for reporting observational studies" [34]; and "Cochrane Handbook for Systematic Reviews of Interventions: Assessing Risk of Bias in Included Studies" [35]. Differences during the extraction process were resolved via discussion by the reviewers with third reviewer involvement when necessary.

\section{Data extraction}

The data extraction was accomplished by two reviewers (EMB and MHK) independently and together from all included articles by using data extraction form prepared in advance. The data and information extracted from every included study were the following: study citation, research approach and design, study area and period, study finding, unit of study and outcome.

\section{Dealing with missing data}

For any ambiguous information found in the included articles, we have tried to contact the Authors even though we failed to found some of them. But, even the authors that we have contacted have not followed and given us the necessary information.

\section{Data synthesis}

Due to the heterogeneous nature of the articles in their finding and outcome variables considered, we have done a detailed discussion thematically.

\section{Results}

\section{Study selection}

All valuable sources for the review were searched and found from different data bases such as Directory of Open Access Journals (DOAJ), Journals, Working Papers \& Conferences in Business Studies and Economics (EconBiz), Education Resources Information Center (ERIC), Google Scholar, Oxford Journals, PubMed, SpringerLink, Europe PMC, Microsoft Academic Search, OAlster and Academic Journals (AJ) and Addis Ababa University (AAU) data base as well as from other sources through March 9 to 10, 2019 using keywords. The key words used were determinants, factors, health insurance, community based health insurance, willingness to utilize, willingness to join, willingness to pay, willingness to uptake, willingness to enroll and Ethiopia. The search was conducted by systematically combining these key words. Totally, 272 records were identified from which 257 were from data bases and the rest 15 from other sources. 79 articles were duplicates and removed by using EndNote X7. After the duplicates were removed, 193 records were screened for eligibility by their title and abstract and 159 were excluded as they were not relevant. Then, 34 articles were found to be 
eligible for full text analysis. Based on full text review, 14 articles were excluded. Finally, 20 articles were included for systematic review (refer to figure $1)$.

Figure 1: Flow diagram of literature screening strategy.

\section{Study characteristics}

7 mixed, 11 quantitative studies and 2 contingent valuation methods were included; totally 20 articles. The more detailed information of the characteristics of the included studies is provided in table 1.

Table 1: Characteristics of studies that met inclusion criteria.

\begin{tabular}{|c|c|c|c|c|c|}
\hline Study ID & Study design & Study area & Study unit & Study outcome & $\begin{array}{l}\text { Funding } \\
\text { source }\end{array}$ \\
\hline Mariam 2003 [22] & $\begin{array}{l}\text { Mixed } \\
\text { approach }\end{array}$ & $\begin{array}{l}\text { Amhara \& } \\
\text { Oromiya }\end{array}$ & Household & Willingness to participate & ACAP \\
\hline Molla 2014 [36] & Cross sectional & Oromiya & Household & Willingness to participate & JU \\
\hline Ololo 2009 [21] & Cross sectional & Oromiya & Household & Willingness to join & JU \\
\hline Haile 2014 [37] & Cross sectional & SNNPR & Household & Willingness to join & JU \\
\hline Kibret 2019 [15] & Cross sectional & Amhara & Household & Willingness to join & - \\
\hline Kassahun 2018 [23] & Cross sectional & Amhara & Household & Willingness to join & - \\
\hline Kebede 2014 [38] & Cross sectional & Amhara & Household & Willingness to pay & - \\
\hline Zewde 2014 [39] & CVM & Addis Ababa & Household & Willingness to pay & - \\
\hline Entele 2016 [40] & CVM & Oromiya & Household & Willingness to pay & - \\
\hline Minyihun 2019 [41] & Cross sectional & Amhara & Household & Willingness to pay & GU \\
\hline Mogessie 2017 [42] & Cross sectional & Amhara & Household & Willingness to pay & DBU, EHIA \\
\hline $\begin{array}{l}\text { Namomsa } 2017 \\
{[43]}\end{array}$ & $\begin{array}{l}\text { Mixed } \\
\text { approach }\end{array}$ & Oromiya & Household & Enrolment \& challenges & - \\
\hline Atnafu 2018 [44] & $\begin{array}{l}\text { Mixed } \\
\text { approach }\end{array}$ & Amhara & Household & Enrollment to $\mathrm{CBHI}$ & - \\
\hline Shibeshi 2017 [45] & $\begin{array}{l}\text { Mixed } \\
\text { approach }\end{array}$ & Oromiya & Household & $\begin{array}{l}\text { Adverse selection and supply side factors to } \\
\text { enroll }\end{array}$ & AAU, OHB \\
\hline Gobena 2018 [46] & Cross sectional & Oromiya & Household & Utilization and factors & MoE, SU \\
\hline Workneh 2017 [17] & Cross sectional & Amhara & Household & Compliance with $\mathrm{CBHI}$ & - \\
\hline Abebe 2014 [47] & $\begin{array}{l}\text { Mixed } \\
\text { approach }\end{array}$ & Amhara & Household & Coverage, intake, enrolment & - \\
\hline Nurie 2017 [48] & $\begin{array}{l}\text { Mixed } \\
\text { approach }\end{array}$ & Oromiya & Household & Determinants to Uptake & - \\
\hline Jembere 2018 [49] & $\begin{array}{l}\text { Mixed } \\
\text { approach }\end{array}$ & Amhara & Household & Attitude to $\mathrm{CBHI}$ & AAU \\
\hline Mirach 2019 [50] & Cross sectional & Amhara & Household & Determinants of $\mathrm{CBHI}$ & - \\
\hline
\end{tabular}

* AAU: Addis Ababa University; ACAP: African Career Awards program; CVM: Contingent Valuation Method; DBU: Debre Berhan University; EHIA: Ethiopia Health Insurance Agency; GU: Gondar University; JU: Jimma University; MoE: Ministry of Education; OHB: Oromiya Health Bureau; SU: Samara University.

\section{Factor analysis}

The utilization of $\mathrm{CBH}$ service was found to be affected by supply-side factors like service availability and coverage [51], skill deficit of CBHI officials and inadequate manpower, budget deficiency to community mobilization, low accessibility of health institutions, delay to fulfill formalities to the insures, absence of registration materials and office inconvenience (narrow); demand side factors (demographic and health perception factors) like 
fail to fulfill formality and providing necessary information for registration and forgetting having receipt in health sectors) [43].; socio-economic factors like participation in Iddirs and health facility factors like service quality and trust [51].

From the demand side, the major factors negatively affecting CBHI utilization were seasonality of income, geographically scattered settlements and mobility of pastoralists and negative perception towards health insurance [12]. Also, with the existence of chronic illness [52], adverse selection (inclusion of chronically ill, poor and indigents; the poorest of the poor) [12, 27, 44] and moral hazards (miss utilizations) during enrolment were the limitations [12,27]. On the other hand, expectation of long enrollment time more than a year with a single payment [53]; consideration of CBHI as profit making and expectation of double registration in a single payment; if not used health service, consider the payment as reserve deposit as well as fail to pay fee and have ID card were found to be challenges [54]. Members of CBHI commonly practice self-medication entails the scheme's utilization was poor even among the members [55].

From the supply side, discrimination between cash and insurance users, bureaucratic complexity in cost reimbursement, lack of trained personnel, adverse selection, fraud and corruption [12]. The health professionals' job satisfaction is negatively related with the health sector reform [56]. Service hour and efficiency of $\mathrm{CBHI}$ service were found to be positively associated with satisfaction of $\mathrm{CBHI}$ scheme [57], work load without additional incentives negatively affects $\mathrm{CBHI}$ utilization [19]. Most of the health institutions were not ready to $\mathrm{CBHI}$ scheme's requirements/criteria [58]. Inadequacy of health sector in terms of quality, organized working practice, resources and premises; forcing members to search for expensive private sectors [54]. Registration time and cost [46], delay in membership card provision had hardily affected CBHI utilization [48].

In comparing the regions that $\mathrm{CBHI}$ has been implementing, households in Amhara and Oromiya regions were found more likely to enroll as compared to households living in Tigray and SNNPR. CBHI members in SNNPR have limited access to tertiary health care services; insured households can use tertiary services only at the nearest public hospital (while those in Amhara may visit any public hospital within the region but those in Oromiya may use care from public hospitals within and outside the region). Insured households in SNNPR cannot claim reimbursements if they use health care services from private providers in the event that medical equipment or drugs are not available in CBHI linked facilities [59]. The determinants are broadly categorized as follows (figure 1).

*PSNP: Productive Safety Net Program

Figure 2: Thematic classification of the factors affecting $\mathrm{CBHI}$ in Ethiopia.

\section{Demographic and socio-economic factors}

The health care effectiveness largely depends on the socio-economic aspects of the family/household [25]. Six and four studies reported that there was a positive relationship between $\mathrm{CBH}$, and being male $[20,38,42,43,46,47]$ and female $[15,21,37,40]$ headed of the households respectively. Being male [38, 42] and female [40] were found to be positively related with the willingness to pay (WTP) for CBHI respectively. Being male was also positively related with enrolment to $[20,43,47]$ and utilization of [46] CBHI. On the other hand, being female was found to be positively associated with the willingness to join (WTJ) to $\mathrm{CBHI}[15,21,37]$. Age was also found to be a positive predictor to $\mathrm{CBHI}$ utilization $[36,43,44,46,48,57,60]$. It was also found to be a negative predictor to the scheme's utilization [17, 20, 37, 40, 61]. Being aged was positively related with the WTJ [36], enrolment to [43, 44, 48], utilization of [46] and WTP for [57, 60] CBHI. But, it was also found that age was a negative predictor to enrolment to [20], WTJ [37], WTP for [40], compliance with [17], and knowledge, attitude and practices of [61]CBHI scheme. Marriage was also well articulated as a determinant for CBHI utilization. Being married was a positive factor to the WTJ to $\mathrm{CBHI}[23,37]$ and enrolment in the scheme [20, 43, 47, 62]. According to family/household size, in most studies, it was a positive predictor for $\mathrm{CBHI}$ utilization $[1,18,20,22,23,37-39,41,42,44-51,62]$. It was also negatively related with satisfaction of $\mathrm{CBHI}$ utilization [40,57]. Family size was positively associated with the WTJ in [1, 23, 37], WTP for [1, 38, 39, 41, 42], participation in [18, 22], enrolment to $[20,44,47,48,50,51,62]$, uptake of $[45,46]$ and attitude of $\mathrm{CBHI}[49]$; but negatively linked with [40,57] the scheme. Pointing to educational status of the household, twenty one studies reported that education was a positive determinant to $\mathrm{CBHI}$ utilization $[1,15,18,21,23,36,38$ $44,46-49,57,60-63]$ while two studies reported it as a negative predictor to scheme uptake [37, 64]. Accordingly, education attainment was a positive predictor of the WTJ $[1,15,21,23,36]$, WTP for $[1,38-42,57]$, participation in [18], enrolment to $[43,44,47,48]$, utilization of [46], attitude to [49, 60], knowledge and practices of [60] and membership to [63] CBHI. But it was a negative predictor of the WTJ [37] and enrolment to [64] CBHI scheme.

Occupational status, such as farming, merchandise and housewife were found to be associated with CBHI utilization. In most studies that reported employment as a predictor to $\mathrm{CBH}$ utilization, it was found to be a positive factor [17, 21, 37, 38, 40,46]. But in one study it was reported that holding occupation was a negative factor for $\mathrm{CBHI}$ utilization [17]. Households who are employed were found to be willing to pay for $\mathrm{CBHI}$ [39]. Being farmer was a positive factor to the WTP for [38, 40], compliance with [17] and utilization of [46] CBHI scheme. Holding merchandise occupation was a positive factor to the WTP for $\mathrm{CBHI}$ [38] but negatively related with the scheme's compliance [17]. Housewife as an occupation was a positive factor for the WTJ in CBHI scheme [21,37]. Regarding to income, including monetary and nonmonetary assets, it was found to be a positive predictor of CBHI utilization [1, 15, 18, 21-23, 36-39, 42, 45-47, 50, 57, 60, 61, 63]; but also a negative determinant [40, 59, 64]. In almost all studies reported income as a determinant factor of $\mathrm{CBHI}$ utilization, it was a positive predictor; income was positively related with the WTJ [1, 15, 21, 23, 37], WTP for [1, 38, 39, 42, 57], willingness to participate in [18, 22], uptake of [45, 46], enrolment to [47, 50], membership to [63], knowledge, attitude and practices of [60] and health care utilization among members of [61] CBHI scheme. However, one study reported that income was negatively related with $\mathrm{CBHI}$ enrolment 
[64]. Ability to pay for health care cost (financial capability) was positively related with the WTJ in CBHI [36]. Livestock size was negatively related with the WTP for CBHI scheme. Poor households (food insecure) had positive interest to the WTP for [40] and enrolment to [59] CBHI.

The other important factor was community participation. This includes local meetings/meeting attendance, membership in Iddir and $/ k u b$ (social capital), PSNP, individual social capital and community level horizontal trust, community solidarity and religious inclination (bond to religious beliefs \& values). Local meetings/community participation/meeting attendance had been found to have positive relationship with $\mathrm{CBHI}$ attitude [49] and enrolment [20,48]. Membership in Iddir and local credit association, i.e. Ikub (social capital, a traditional credit package) [15, 21, 37, 42, 44, 51, 59] and PSNP [32, 59, 64-66] had positive relationship with CBHI utilization. Participation in Iddir and Ikub was positively related with the WTJ in [15, 21, 37], WTP for [42] and enrolment to [44, 51, 59] CBHI scheme. PSNP was a positive predictor to the uptake of [32], membership of [64], enrolment to [59], modern health care utilization related $[65,66] \mathrm{CBHI}$. On the other hand, PSNP was also negatively related with CBHI utilization [20]. Individual social capital and community level horizontal trust had positive associations with the probability of WTJ in CBHI [37]. Community solidarity was positively linked with $\mathrm{CBHI}$ enrolment [50]. Religious inclination (bond to religious beliefs \& values) was not only a positive predictor of enrolment to CBHI [59] but also a negative determinant of WTJ in the scheme [36].

Table 2: Summary of demographic and socio-economic factors in the included studies.

\begin{tabular}{|c|c|c|c|c|c|c|c|c|c|}
\hline \multirow[t]{4}{*}{ Year of study } & \multicolumn{9}{|c|}{ Variables } \\
\hline & & & Age & Education & Income & Community participation & Marriage & Occupation & Family size \\
\hline & \multicolumn{2}{|l|}{ Sex } & & & & & & & \\
\hline & Male & Female & & & & & & & \\
\hline Mariam 2003 [22] & & & & & ü & & & & ü \\
\hline Ololo 2009 [21] & & & & $\ddot{u}$ & $\ddot{u}$ & $\ddot{u}$ & & $\ddot{u}$ & \\
\hline Molla 2014 [36] & & & $\ddot{\mathrm{u}}$ & ü & & $\hat{\mathbf{u}}$ & & & \\
\hline Haile 2014 [37] & & & $\hat{\mathbf{u}}$ & $\hat{\mathbf{u}}$ & $\ddot{\mathrm{u}}$ & $\ddot{\mathrm{u}}$ & $\ddot{\mathbf{u}}$ & $\ddot{\mathrm{u}}$ & ü \\
\hline Kebede 2014 [38] & $\ddot{u}$ & & & $\ddot{u}$ & $\ddot{u}$ & & & $\ddot{u}$ & $\ddot{u}$ \\
\hline Zewde 2014 [39] & & & & $\ddot{\mathbf{u}}$ & $\ddot{u}$ & & & $\ddot{\mathrm{u}}$ & $\ddot{\mathrm{u}}$ \\
\hline Kibret 2019 [15] & & $\ddot{\mathrm{u}}$ & & ü & ü & $\ddot{\mathrm{u}}$ & & & \\
\hline Workneh 2017 [17] & & & $\hat{\mathbf{u}}$ & & & & & ü & \\
\hline Kassahun 2018 [23] & & & & $\ddot{\mathrm{u}}$ & $\ddot{\mathrm{u}}$ & & ü & & $\ddot{\mathrm{u}}$ \\
\hline Minyihun 2019 [41] & & & & ü & ü & & & & ü \\
\hline Entele 2016 [40] & & $\ddot{\mathrm{u}}$ & $\hat{\mathbf{u}}$ & ü & & & & $\ddot{\mathbf{u}}$ & $\hat{\mathbf{u}}$ \\
\hline Shibeshi 2017 [45] & & & & & $\ddot{u}$ & & & & ü \\
\hline Mogessie 2017 [42] & $\ddot{u}$ & & & ü & ü & $\ddot{\mathrm{u}}$ & & & $\ddot{\mathrm{u}}$ \\
\hline Namomsa 2017 [43] & $\ddot{\mathbf{u}}$ & & $\ddot{\mathbf{u}}$ & $\ddot{\mathbf{u}}$ & & & $\ddot{\mathbf{u}}$ & & \\
\hline Jembere 2018 [49] & & & & ü & & ü & & & $\ddot{u}$ \\
\hline Mirach 2019 [50] & & & & & ü & & & & $\ddot{u}$ \\
\hline Nurie 2017 [48] & & & $\ddot{\mathrm{u}}$ & ü & & $\ddot{\mathrm{u}}$ & & & $\ddot{\mathrm{u}}$ \\
\hline Gobena 2018 [46] & $\ddot{u}$ & & $\ddot{\mathbf{u}}$ & $\ddot{\mathbf{u}}$ & ü & & & $\ddot{u}$ & $\ddot{\mathbf{u}}$ \\
\hline Atnafu 2018 [44] & & & $\ddot{\mathrm{u}}$ & ü & & $\ddot{\mathrm{u}}$ & & & ü \\
\hline Abebe 2014 [47] & & $\hat{u}$ & & ü & $\ddot{u}$ & & ü & & ü \\
\hline
\end{tabular}

\section{ü Positive Correlation; û Negative correlation}

\section{Health status and health service related factors}

Illness, including chronic and frequency of illness, in almost all studies that reported it as a predictor to the utilization of CBHI, the presence of morbidity/chronic illness and illness experience had positive relationship with the scheme's utilization [22, 27, 36, 39-42, 45-48, 50, 61, 62]. IIIness was a positive determinant of the WTP for [39-42], participation in [22], WTJ [36], enrolment to [47, 48, 50, 62], Knowledge, attitude and practice [61], access, use and quality of healthcare services related to [27] $\mathrm{CBHI}$ scheme. The frequency of illness was positively related with the uptake of [45, 46] and 
enrolment to [48] CBHI. However, good health perception of the family was negatively related with $\mathrm{CBHI}$ utilization [36, 39, 44, 46, 50, 51]. It was negatively related with the WTP for [39], WTJ [36], enrolment to [44, 50,51] and utilization of [46] CBHI.

In all studies that reported premium as a predictor of $\mathrm{CBHI}$ utilization, it was found that premium amount was negatively related with the scheme's utilization [17, 22, 36-38, 46]. Premium cost was a negative predictor to the WTJ [36, 37], participation in [22], WTP for [38], compliance with [17] and utilization of [46] CBHI. Previous health care expenditure, including OOP expense and borrowing, was also predictors for $\mathrm{CBHI}$ utilization. Previous OOP expense for health service was positively related with the scheme's utilization [20,40,61,62]. OOP expense was positively associated with enrolment to $[20,61,62]$ and WTP for [40] CBHI. But it was reported that OOP was better than CBHI; i.e., negative predictor to the WTP for CBHI [38]. Experience of borrowing money for health care service was positively related with the WTJ the scheme [15, 37].

Awareness, including information, attitude/perception \& readiness to start/renew the service, was found to be a predictor for CBHI enrolment. In all studies reported it as a factor to determine $\mathrm{CBHI}$ utilization, information level was found to be a positive predictor to the scheme's utilization.

Accordingly; knowledge, awareness and information levels were found to be positively related with CBHI utilization [12, 17, 18, 20, 36, 41-46, 48-50, 53, $61,64,67]$. Awareness level was a positive predictor in the interest to [12], participate in [18], comply with [17], enrolment to [20, 43, 44, 48, 50, 53, 64, 67] , WTJ [36], the attitude towards [49, 61], the knowledge and practice of [61], the WTP for [41, 42], uptake of [45, 46] and be a member in [61] CBHI scheme. The attitude towards sense of ownership of the households with CBHI was also a positive predictor [49]. Positive attitude/perception \& readiness to start/renew the service was positively related to compliance with [17], WTJ [36] and uptake [45] the scheme.

Service status, including quality, availability, accessibility, coverage, adequacy, efficiency of health service and capacity and readiness of health facility, health sector distance, travel time, waiting time, trust on service provided by $\mathrm{CBHI}$ scheme, was also found to be a significant predictor for the scheme's utilization. Quality, availability, accessibility, coverage, adequacy of health service and capacity and readiness of health facility were positively related with scheme uptake [12, 36, 38, 40, 42, 44, 46-48, 50, 51, 53, 54, 61, 62, 64]. Service adequacy was positively related with the interest to [12], WTP for [38, 40, 42], WTJ [36], enrolment to [44, 47, 48, 50, 51, 62, 64], the knowledge, attitude and practice to be a member in [61] to satisfy with [53, 54] and utilization of [46] CBHI. Insufficiency of health service both in equipment and human power was a negative predictor to the scheme's utilization [12].

Table 3: Summary of health status and health service related factors in the included studies. 
Study ID Variables

\begin{tabular}{|c|c|c|c|c|c|c|c|c|c|c|c|}
\hline & Illness & Premium & $\begin{array}{l}\text { Benefit } \\
\text { package }\end{array}$ & Awareness & Healthiness & $\begin{array}{l}\text { Service } \\
\text { quality }\end{array}$ & Distance & $\begin{array}{l}\text { Waiting } \\
\text { time }\end{array}$ & Borrowing & Trust & $\begin{array}{l}\text { Bureaucratic } \\
\text { complexity }\end{array}$ \\
\hline $\begin{array}{l}\text { Mariam } \\
2003[22]\end{array}$ & $\ddot{u}$ & $\hat{\mathbf{u}}$ & & & & & & & & & \\
\hline \multicolumn{12}{|l|}{$\begin{array}{l}\text { Ololo } \\
2009 \text { [21] }\end{array}$} \\
\hline $\begin{array}{l}\text { Molla } \\
2014 \text { [36] }\end{array}$ & $\ddot{u}$ & û & $\ddot{u}$ & ü & $\hat{u}$ & ü & & & & ü & \\
\hline $\begin{array}{l}\text { Haile } \\
2014 \text { [37] }\end{array}$ & & û & & & & & û & & ü & & \\
\hline $\begin{array}{l}\text { Kebede } \\
2014 \text { [38] }\end{array}$ & & û & & ü & & ü & & & & & \\
\hline $\begin{array}{l}\text { Zewde } \\
2014 \text { [39] }\end{array}$ & & & & & $\hat{u}$ & & & & & & \\
\hline $\begin{array}{l}\text { Kibret } \\
2019 \text { [15] }\end{array}$ & & & & & & & & & ü & & \\
\hline $\begin{array}{l}\text { Workneh } \\
2017 \text { [17] }\end{array}$ & & û & & $\ddot{u}$ & & & & & & & \\
\hline \multicolumn{12}{|l|}{$\begin{array}{l}\text { Kassahun } \\
2018 \text { [23] }\end{array}$} \\
\hline $\begin{array}{l}\text { Minyihun } \\
2019 \text { [41] }\end{array}$ & ü & & & ü & & & & & & & \\
\hline $\begin{array}{l}\text { Entele } \\
2016 \text { [40] }\end{array}$ & ü & & & & & ü & & û & & & \\
\hline $\begin{array}{l}\text { Shibeshi } \\
2017 \text { [45] }\end{array}$ & $\ddot{u}$ & & & ü & & & & & & $\ddot{u}$ & \\
\hline $\begin{array}{l}\text { Mogessie } \\
2017 \text { [42] }\end{array}$ & ü & & & ü & & ü & & & & ü & \\
\hline $\begin{array}{l}\text { Namomsa } \\
2017 \text { [43] }\end{array}$ & & & & ü & & & & & & & \\
\hline $\begin{array}{l}\text { Jembere } \\
2018 \text { [49] }\end{array}$ & & & ü & & & & & & & & \\
\hline $\begin{array}{l}\text { Mirach } \\
2019[50]\end{array}$ & ü & & ü & ü & û & ü & & & & & \\
\hline $\begin{array}{l}\text { Nurie } \\
2017 \text { [48] }\end{array}$ & ü & & & ü & & ü & $\hat{u}$ & & & ü & \\
\hline $\begin{array}{l}\text { Gobena } \\
2018[46]\end{array}$ & ü & û & & ü & $\hat{u}$ & ü & $\hat{u}$ & $\hat{u}$ & & $\ddot{u}$ & \\
\hline $\begin{array}{l}\text { Atnafu } \\
2018 \text { [44] }\end{array}$ & & & ü & ü & $\hat{u}$ & ü & & & & & \\
\hline $\begin{array}{l}\text { Abebe } \\
2014 \text { [47] }\end{array}$ & $\ddot{\mathbf{u}}$ & & $\ddot{\mathrm{u}}$ & & & $\ddot{u}$ & & & & & $\hat{\mathbf{u}}$ \\
\hline
\end{tabular}

\section{ü Positive Correlation; û Negative correlation}

Laboratory service provision was positively related with the uptake of $\mathrm{CBHI}[53,57]$. Availability of medical equipment was positively related with the WTP for [40] and enrolment to [44,59] scheme. It was reported that health service delivery system provided by CBHI scheme was not satisfactory in terms of quality, referral system, human resource and building facility [54]. Prior health insurance \& health service utilization was reported as both positive [42] and negative [20] predictor for the WTP and enrolment to CBHI respectively. Health sector distance was negatively related with the participation in [18], enrolment to and WTJ [37] CBHI. Travel time was negatively associated with the enrolment to the scheme [59, 62]. Waiting time was also negatively related with the WTP for [40] and utilization of [46] CBHI. Trust on CBHI scheme was positively related with the WTJ [36], WTP for [42], enrolment to $[48,51]$ to uptake $[44,46]$ the scheme. According to benefit package, service availability and coverage; proper benefit package and adequacy had positive relationship with the WTJ [36], enrolment to [44, 47, 50] and attitude towards [49] CBHI. Regarding to governance, administrative complexity was found to be a negative predictor to enroll to $\mathrm{CBHI}$ [47]. 
Figure 3: Summary of the determinants of $\mathrm{CBHI}$ in Ethiopia.

\section{Discussion}

In this review, studies with quantitative, qualitative and mixed approach methods were included. Most studies included in the review used cross sectional approach. This review revealed that the factors that affect $\mathrm{CBHI}$ utilization in Ethiopia can be grouped into: Demographic and socioeconomic factors; and health status and health service related factors.

\section{Demographic and socio-economic factors}

Gender was found to be significant predictor of $\mathrm{CBHI}$ utilization. However, neither maleness nor femaleness has found to be a clear predictor of $\mathrm{CBHI}$. This review revealed that as the household head became male, the willingness to utilize (WTU) CBHI was found to be increased; i.e., households which were headed by male were more willing to utilize $\mathrm{CBHI}$ scheme as compared to those households that were being led by females [20, 38, $42,43,46,47]$. Oppositely, as the head of the family became female, the WTU the scheme was found to be increased. Families which were headed by female were more willing to utilize the scheme as compared to those families that were being led by men $[15,21,37,40]$. On the other hand, as the household head became female, the WTU the scheme was found to be decreased [47]. Regarding to age of the family members, no consistent result was found; the results of the included studies were not found to be consistent. Older individuals were more willing to utilize the scheme than younger ones [36, 43,44 $46,48,57,60]$. On the other side, if most of the family members became younger, the WTU the scheme was found to be increased; i.e., since the scheme covers family members up to 18 years of age, families with greater younger members were more willing to utilize the scheme than those families with older members [17, 20, 37, 40,61]. With respect to marriage, the WTU the scheme was found to be more among those who were married than those who were not which entails us that social work is mandatory to keep intact family; minimizing/avoiding divorce to protect the family is important to increase CBHI utilization [20, 23, 37, 43, 47, 62]. Regarding to family size, as it increased; the WTU the scheme did so. Those households with large family size were more willing to uptake the scheme than those households with small family size [1, 18, 20, 22, 23, 37-39, 41, 42, 44-51, 62]. However, as family size increased, the payment for the premium also increased. As a result, satisfaction with $\mathrm{CBH}$ utilization was decreased with increased family size $[40,57]$. Considering educational level of the household, as educational attainment becomes advanced, the tendency to utilize $\mathrm{CBH}$ scheme was found to be appreciable; as educational attainment increased; awareness level to the scheme was also increased accordingly [1, 15 , $18,21,23,36,38-44,46-49,57,60-63]$. But, due to negative attitude to the scheme, it was also reported that as educational attainment increased, the WTU the scheme was found to be decreased [37, 64].

With respect to income including monetary and nonmonetary assets, except some studies [40, 59, 64], the report of all articles were consistent. As income of the family becomes increased, they could be able to afford the premium, thus, the decision to utilize the scheme was also found to be analogously increased $[1,15,18,21-23,36-39,42,45-47,50,60,61,63]$. Oppositely, as livestock size increased, the WTU CBHI was found to be decreased; that means, wealth households were not interested to utilize the scheme; i.e., livestock considered to be the reserved asset of the family [40] whereas food insecure families were found to be interested to use it in that they could not afford to pay the expensive 00P payment [40,59, 64]. Regarding to occupation, the WTU the scheme was higher among those households being led by heads who were employed than those who were not [39]. The WTU the scheme was found to be increased with being housewife [21, 37] , farmer [17, 38, 40, 46] and merchant [38]. However, the WTU the scheme was also found to be less among merchants [17].

Community participation, here, which is defined as peoples interaction or involvement aimed to solve critical problems in the respected society was also an important factor. Households that were known to participate in local meetings were more willing to utilize $\mathrm{CBH}$ than those households did not attend [20,48,49]. Households which were members in Iddir and $I k u b[15,21,37,42,44,51,59]$ and PSNP [32, 59, 64-66] were found to be more willing to uptake the scheme than those households that were not. But, participation in PSNP was also known to decrease the WTU the scheme [20]. The WTU the scheme was found to be more likely among those families depend on individual social capital and community level horizontal trust [37]. As social bond or community solidarity increased, the tendency to utilize the scheme was found to be more likely [50]. Due to the ideology difference of different religions, the interest to uptake the scheme was found to be less [36] or more [59] among households having bond to religious beliefs \& values.

\section{Health status and health service related factors}

Chronic illness requires continuous follow-up and prescription refill which in turn devoted to incur huge expense. Consequently, the WTU the scheme were more among those families with morbidity/chronic illness and illness experience than those who were free of it [22, 27, 36, 39-42, 45-48, 50, 61, 62]. Oppositely, the WTU the scheme was found to be decreased with good perceived health status or self-rated healthiness of the family; i.e., if the perceived health status of the family was increased, the WTU the scheme was decreased [36, 39, 44, 46, 50, 51].

As premium cost increased, its affordability decreased. Thus, the WTU the scheme was found to be decreased with higher premium cost [17, 22, 36-38, 46]. As income of the family increased, the premium became affordable, thus, the decision to utilize the scheme was also found to be analogously increased $[1,15,18,21-23,36-39,42,45-47,50,60,61,63]$. However, as the premium becomes increased, the utilization of the scheme found to be decreased $[17,22,36-38,46]$. In reverse, with respect to experience of health care service cost expenditure, the households that were experienced previous OOP expense for health service were more willing to use the scheme than those households did not [20, 40, 61, 62]. But it was also reported that OOP payment was better than $\mathrm{CBHI}$ [38]. However, households experienced borrowing money for health care service to pay OOP payment were more interested to use the scheme than those households did not borrow for that [15, 37]. Accordingly awareness level, as knowledge and information 
about CBHI increased, the WTU the scheme also found to be increased $[12,17,18,20,36,41-46,48-50,53,61,64,67]$. However, the tendency to utilize the scheme was found to be increased with the attitude towards sense of ownership of the households with CBHI. The WTU the scheme was found to be appreciable if unused premium was reserved for future use as a deposit for the payer for the future [49].

The WTU the scheme was increased with the increased quality, availability, accessibility, coverage, adequacy of health service and capacity and readiness of health facility $[12,36,38,40,42,44,46-48,50,51,53,54,61,62,64]$. The WTU the scheme was found to be decreased with insufficiency of health service both in equipment and human power [12]. If laboratory service provision was available, the WTU the scheme was more likely [53, 57]. If the health facilities were well furnished, the WTU the scheme was increased $[40,44,59]$. However, it was reported that health service delivery system provided by $\mathrm{CBHI}$ scheme was not satisfactory in terms of quality, referral system, human resource and building facility [54]. Experience of prior health insurance \& health service utilization found to be either increased [42] or decreased [20] the WTU the scheme. While the health sector distance increased, the WTU the scheme decreased $[18,37]$. If the time to access the health institution was difficult; if it was too far to reach, then the WTU the scheme become decreased [59, 62]. If the waiting time to be served in the institution was too long, the WTU the scheme was unlikely [40, 46]. If the service to be provided by CBHI was traceable (amenable), the WTU the scheme was found to be increased [36, 42, 44, 46, 48, 51]. Regarding to the package constituted in $\mathrm{CBHI}$ service, as the benefit package to be covered by the scheme becomes increased, the health service to be obtained from the scheme would be adequate. Hence, as the benefit package to be provided by CBHI increased, the WTU it increased. The uptake of the scheme was also found to be increased with service availability, coverage and adequacy $[36,44,47,49,50]$. But, the tendency and WTU the scheme was found to be decreased with administrative complexity [47].

\section{Limitations}

Since most of the resources included were cross sectional studies, it was not easy to analyze the true temporal relationship; the exact direction of relationship of the association of each variable (factor). There were also relationship differences for certain variables; the factor that was significant in one study was not to another study or significant in reverse. On the other hand, most of the studies were from the demand side only. One study was also ongoing study (study waiting for publication; the available portion was only the abstract) [67]. The other one study from AAU website was not full; i.e., only its abstract was similar to its title, but the full PDF was a different study [60]. These studies therefore excluded even if they were deemed to be included. For certain studies, we faced difficulty to contact authors whenever ambiguity was in place.

\section{Conclusions}

This review pointed out that the determinants of CBHI utilization include both supply and demand side factors which were thematically grouped into demographic and socio-economic (including gender, age, income, education, community participation, marriage, occupation, family size and health status and health service related factors (including illness, premium, benefit package, awareness, expenditure, health status, service status and bureaucratic or administrative complexity). Even if there was no consistent finding regarding to the relationship of gender and age with $\mathrm{CBH}$ utilization; the factors like income, education, community participation, marriage, occupation, family size, illness experience, benefit package, awareness, previous OOP expenditure, service quality and trust were found to be positively related with the schemes utilization. However, premium amount, self-rated health status, and bureaucratic complexity were negative predictors. According to this review, in order to achieve UHC through $\mathrm{CBHI}$, it is recommended that special attention should be given to devote to increase income of the family by creating opportunities to occupation, increasing awareness through education on $\mathrm{CBHI}$, appreciating community participation according to indigenous social arrangements, keeping intact family (marriage) by monitoring through social work focusing on vital statistics, finding a means to address $\mathrm{CBH}$ service according to family size, increasing benefit package to be provided by the scheme with health service quality, efficiency and accessibility, and working on premium amount to be affordable and ensuring good governance.

\section{Abbreviations}

CBHI: Community-Based Health Insurance; OOP: Out of Pocket; PSNP: Productive Safety Net Program; SNNP: Southern Nations Nationalities and Peoples; UHC: Universal Healthcare Coverage; WTJ: Willingness to Join; WTP: Willingness to Pay; WTU: Willingness to Utilize.

\section{Declarations}

\section{Ethics approval and consent to participate}

The review was approved by "Ethical Review Committee" of Department of Pharmacy in Medicine and Health Science College of Wollo University.

\section{Consent for publication}

Not applicable.

\section{Availability of data and materials}

The data and materials are available from the corresponding author with justifiable request. 
Competing interests

The authors declare that they have no competing interests.

\section{Funding}

Not applicable.

Authors' contributions

EMB (mekashawe@gmail.com) and MHK (yeabdrug@gmail.com) designed the study, extracted and analyzed data; and made critical revision of the manuscript. BDW (birdpharma@gmail.com) participated in the data extraction process and drafted the initial manuscript. All authors approved the manuscript for submission.

\section{Acknowledgments}

Our gratitude is goes to 'Senay Drug Store' situated in Dessie Town, Ethiopia for providing us confortable open office during data extraction and analysis; and to access free internet service.

Authors' information

${ }^{1}$ Lecturer (MSc.) at Social and administrative pharmacy unit, Department of Pharmacy, Wollo University, Ethiopia; ${ }^{2}$ Assistant Professor (PhD) at Social and administrative pharmacy unit, Department of Pharmacy, Wollo University, Ethiopia; ${ }^{3}$ Assistant Professor (PhD fellow at Addis Ababa University) at Social and administrative pharmacy unit, Department of Pharmacy, Wollo University, Ethiopia.

\section{References}

1. Asfaw A, Braun Jv. Can community health insurance schemes shield the poor against the downside health effects of economic reforms? The case of rural ethiopia. Health Policy 2004, 70(1):97-108. DOI: 10.1016/j.healthpol.2004.02.005.

2. S.Feleke, W.Mitiku, H.Zelelew, T.Ashagari. Ethiopia's community-based health insurance: a step on the road to universal health coverage. Washington: World Bank Group 2015.

3. G.Richard. Reviewing Ethiopia's health system development. JMAJ 2009, 52(4):279-286.

4. Ali EE. Health Care Financing in Ethiopia: Implications on Access to Essential Medicines. Value in Health Regional Issues 2014, 4:37-40. DOI: 10.1016/j.vhri.2014.06.005.

5. Alebachew A, Yusuf Y, Mann C, Berman P. Ethiopia's Progress in health financing and the contribution of the 1998 health care and financing strategy in Ethiopia. MA, Addis Ababa: Harvard TH Chan School of Public Health and Breakthrough International Consultancy, PLC 2015.

6. Zelelew H. Health care financing reform in Ethiopia: improving quality and equity. Bethesda (MD): Health Systems 2018, 20:20.

7. Asfaw A, Braun JV. Innovations in health care financing: New evidence on the prospect of community health insurance schemes in the rural areas of Ethiopia. International journal of health care finance and economics 2005, 5(3):241-253.

8. FMOH. Health sector transformation plan (2015/16-2019/20): Ministry of Health Addis Ababa; 2015.

9. Alebachew A, Hatt L, Kukla M. Monitoring and Evaluating Progress towards Universal Health Coverage in Ethiopia. PLoS Medicine 2014, 11(9). DOI: 10.1371/journal.pmed.1001696.

10. Mekonen AM, Gebregziabher MG, Teferra AS. The effect of community based health insurance on catastrophic health expenditure in Northeast Ethiopia: A cross sectional study. PloS One 2018, 13(10):e0205972. DOI: 10.1371/journal.pone.0205972.

11. Tilahun $\mathrm{H}$, Atnafu DD, Asrade G, Minyihun A, Alemu YM. Factors for healthcare utilization and effect of mutual health insurance on healthcare utilization in rural communities of South Achefer Woreda, North West, Ethiopia. Health Economics Review 2018, 8(1):15. DOI: 10.1186/s13561018-0200-z.

12. Dibaba A, Ababor S, Y.Assefa. Improving health care financing in Ethiopia (SURE policy brief). Addis Ababa: Ethiopian Public Health Institute 2014.

13. Hallalo H. Achieving Universal Health Coverage through Health Financing Reform: Ethiopian Showcase. Health Economics \& Outcome Research: Open Access 2018, 4(1):1-5. DOI: 10.4172/2471-268X.1000148.

14. FMOH. Health Sector Development Program IV (2010/11-2014/15): Addis Ababa, FMOH; 2010.

15. Kibret GD, Leshargie CT, Wagnew F, Alebel A. Willingness to join community based health insurance and its determinants in East Gojjam zone, Northwest Ethiopia. BMC Res Notes 2019, 12(1):31. DOI: 10.1186/s13104-019-4060-3.

16. Mebratie A. Essays on evaluating a community based health insurance scheme in rural Ethiopia; 2015.

17. Workneh SG, Biks GA, Woreta SA. Community-based health insurance and communities' scheme requirement compliance in Thehuldere district, northeast Ethiopia: cross-sectional community-based study. Clinicoecon Outcomes Res 2017, 9:353-359. DOI: 10.2147/CEOR.S136508. 
18. Gebremeskel T. The impact of community based health insurance in health service Utilization in Tigray: A Case of kilte Awlaelo woreda. Thesis. Mekelle University; 2014.

19. Yismaw M. Role of Community Based Health Insurance on Health Service provision and Healthcare Seeking Behavior of Households in Rural Ethiopia: the Case of Tehuledere District, South Wollo Zone. Thesis. Addis Ababa University; 2017.

20. Haileselassie H. Socio Economic Determinants of Community Based Health Insurance The Case of Kilte Awelaelo District, Tigray Regional State. PhD Thesis. St. Mary's University; 2014.

21. Ololo S, Jirra C, Hailemichael Y, Girma B. Indigenous Community Insurance (IDDIRS) as an alternative health care financing in Jimma city, Southwest Ethiopia. Ethiopian Journal of Health Sciences 2009, 19(1).

22. Mariam DH. Indigenous social insurance as an alternative financing mechanism for health care in Ethiopia (the case of eders). Social Science \& Medicine 2003, 56(8):1719-1726. DOI: 10.1016/S0277-9536(02)00166-1.

23. Kassahun S, Andargie G, Atnafu DD. Willingness to join a village-based health insurance scheme (Iddir) in Dessie town, Ethiopia. Ethiopian Journal of Health Development 2018, 32(4).

24. Barnett I, Tefera B. Poor Households' Experiences and Perception of User Fees for Healthcare: a mixed-method study from Ethiopia: Young Lives; 2010.

25. Onarheim KH, Sisay MM, Gizaw M, Moland KM, Norheim OF, Miljeteig I. Selling my sheep to pay for medicines - household priorities and coping strategies in a setting without universal health coverage. BMC Health Serv Res 2018, 18(1):153. DOI: 10.1186/s12913-018-2943-y.

26. Jembere MY. The Role of Community Based Health Insurance Scheme on Financial Protection and Healthcare Seeking Behavior of Households in District, Northeast Ethiopia. International Journal of Health Economics and Policy 2018, 3(2):13. D0I: 10.11648/j.hep.20180302.11.

27. Jembere MY. Community Based Health Insurance Scheme as a New Healthcare Financing Approach in Rural Ethiopia: Role on Access, Use and Quality of Healthcare Services, the Case of Tehuledere District, South Wollo Zone, Northeast Ethiopia. Family Medicine \& Medical Science Research 2018, 07(02). DOI: 10.4172/2327-4972.1000227.

28. Mebratie AD, Sparrow R, Yilma Z, Abebaw D, Alemu G, Bedi AS. The impact of Ethiopia's pilot community based health insurance scheme on healthcare utilization and cost of care. Soc Sci Med 2019, 220:112-119. DOI: 10.1016/j.socscimed.2018.11.003.

29. Yilma Z, Mebratie A, Sparrow R, Dekker M, Alemu G, Bedi AS. Impact of Ethiopia's Community Based Health Insurance on Household Economic Welfare. The World Bank Economic Review 2015, 29(suppl 1):S164-S173. DOI: 10.1093/wber/lhv009.

30. Lavers T. Social protection in an aspiring 'developmental state': The political drivers of Community-Based Health Insurance in Ethiopia. 2016.

31. Kassie G, Tefera B. Effects of community-based health insurance on modern family planning utilization in Ethiopia. Gates Open Research 2019, 3:1461. DOI: 10.12688/gatesopenres.12960.1.

32. Shigute Z, Mebratie AD, Sparrow R, Yilma Z, Alemu G, Bedi AS. Uptake of health insurance and the productive safety net program in rural Ethiopia. Social Science \& Medicine 2017, 176:133-141. DOI: 10.1016/j.socscimed.2017.01.035.

33. Adebayo EF, Ataguba JE, Uthman OA, Okwundu Cl, Lamont KT, Wiysonge CS. Factors that affect the uptake of community-based health insurance in low-income and middle-income countries: a systematic protocol. BMJ Open 2014, 4(2):e004167. D0I: 10.1136/bmjopen-2013-004167.

34. Elm Ev, Altman DG, Egger M, Pocock SJ, Gøtzsche PC, Vandenbroucke JP. Strengthening the reporting of observational studies in epidemiology (STROBE) statement: guidelines for reporting observational studies. BMJ 2007, 335(7624):806-808. D0I: 10.1136/bmj.39335.541782.AD.

35. Higgins JPT, Altman DG. Assessing Risk of Bias in Included Studies. In: Cochrane Handbook for Systematic Reviews of Interventions. edn.: John Wiley \& Sons, Ltd; 2008: 187-241.

36. Molla A, Fentahun N. Predictors of willingness to participate in health insurance services among the community of Jimma town, Southwest Ethiopia. Health services insights 2014, 7:HSI-S18046.

37. Haile M, Ololo S, Megersa B. Willingness to join community-based health insurance among rural households of Debub Bench District, Bench Maji Zone, Southwest Ethiopia. BMC Public Health 2014, 14:591. DOI: 10.1186/1471-2458-14-591.

38. Kebede A. Willingness to Pay for Community Based Health Insurance among Households in the Rural Community of Fogera District, North West Ethiopia. International Journal of Economics, Finance and Management Sciences 2014, 2(4):263. DOI: 10.11648/j.ijefm.20140204.15.

39. Zewde IF. Demand for health insurance: a study on the feasibility of health insurance schemes for community based groups in Addis Ababa city. Ethiopian Journal of Economics 2014, 23(1):61-86.

40. Entele BR, Emodi NV. Health Insurance Technology in Ethiopia: Willingness to Pay and Its Implication for Health Care Financing. American Journal of Public Health Research 2016, 4(3):98-106. DOI: 10.12691/ajphr-4-3-4.

41. Minyihun A, Gebregziabher MG, Gelaw YA. Willingness to pay for community-based health insurance and associated factors among rural households of Bugna District, Northeast Ethiopia. BMC Res Notes 2019, 12(1):55. DOI: 10.1186/s13104-019-4091-9.

42. Mogessie EM, Bekele G. Households' Willingness to Pay for Community Based Health Insurance Scheme: in Kewiot and EfratanaGedem Districts of Amhara Region, Ethiopia. Business and Economic Research 2017, 7(2):212. DOI: 10.5296/ber.v7i2.11513.

43. Namomsa G. "Community Based Health Insurance Practice/Enrollment and Challenges in Ethiopia Case of Oromiya Regional State Rural Community of Aleltu District”. Thesis. Addis Ababa University; 2017. 
44. Atnafu A, Kwon S. Adverse selection and supply-side factors in the enrollment in community-based health insurance in Northwest Ethiopia: A mixed methodology. Int J Health Plann Manage 2018, 33(4):902-914. DOI: 10.1002/hpm.2546.

45. Shibeshi S. Assessment of factors Affecting Uptake of Community Based Health Insurance among Sabata Hawas Woreda Community, Oromiya Region. Thesis. Addis Abeba Universty; 2017.

46. Gobena T, Dessie Y, Negash B. Community Based Health Insurance Utilization and Associated Factors among Informal Workers in Gida Ayana District, Oromia Region, West Ethiopia. PhD Thesis. Haramaya University; 2018.

47. Abebe M, Degu Y. Assessment Of Ethiopian Community Based Health Insurance at South Achefer Woreda, W/Gojjam, Amhara Regional State. Thesis. Addis Ababa University; 2014.

48. Nurie A. Demographic and Socio-Economic Determinants of Community Based Health Insurance Uptake in Deder, Oromia; Ethiopia. Thesis. Addis Ababa University; 2017.

49. Jembere MY. Attitude of Rural Households towards Community Based Health Insurance in Northeast Ethiopia, the Case of Tehuledere District. Primary Health Care Open Access 2018, 08(03). DOI: 10.4172/2167-1079.1000303.

50. Mirach TH, Demissie GD, Biks GA. Determinants of community-based health insurance implementation in west Gojjam zone, Northwest Ethiopia: a community based cross sectional study design. BMC Health Serv Res 2019, 19(1):544. DOI: 10.1186/s12913-019-4363-z.

51. Kwon S. Community-Based Health Insurance in Ethiopia: Enrollment, memebrship renewal, and effects on health service utilization. PhD Thesis. Seoul National University; 2018.

52. Terfasa TG. Community-Based Health Insurance Coverage, Dropout Rate and Factors associated with among Households in Selected Districts of West Shoa Zone, Ethiopia 2017/18. In: 30th EPHA Annual Conference.

53. Kebede KM, Geberetsadik SM. Household satisfaction with community-based health insurance scheme and associated factors in piloted Sheko district; Southwest Ethiopia. PloS One 2019, 14(5):e0216411. DOI: 10.1371/journal.pone.0216411.

54. Tesfagiorgis E. The Impact of Community-based Health Insurance on Health Service Utilization in Aneded Woreda. 2016.

55. Begashaw B, Tesema S, Tefera E, Kumalo A. Self medication practice in Limmu Genet, Jimma zone, south west Ethiopia: Does community based health insurance scheme has influence? Journal of Pharmaceutics 2018, 9:20. DOI: 10.1155/2018/1749137.

56. Manyazewal T, Matlakala MC. Beyond patient care: the impact of healthcare reform on job satisfaction in the Ethiopian public healthcare sector. Hum Resour Health 2017, 15(1):10. DOI: 10.1186/s12960-017-0188-1.

57. Badacho AS, Tushune K, Ejigu Y, Berheto TM. Household satisfaction with a community-based health insurance scheme in Ethiopia. BMC Res Notes 2016, 9(1):424. DOI: 10.1186/s13104-016-2226-9.

58. Abazinab S, Woldie M, Alaro T. Readiness of Health Centers and Primary Hospitals for the Implementation of Proposed Health Insurance Schemes in Southwest Ethiopia. Ethiopian Journal of Health Sciences 2016, 26(5):449-456.

59. Mebratie AD, Sparrow R, Yilma Z, Alemu G, Bedi AS. Enrollment in Ethiopia's Community-Based Health Insurance Scheme. World Development 2015, 74:58-76. DOI: 10.1016/j.worlddev.2015.04.011.

60. Gisha A. Willingness to pay for Community Based Health Insurance and Its Determinants among Households in Wondo District, Oromia Region, South East Ethiopia. Thesis. Addis Abeba Universty; 2017.

61. Burrowes S. Knowledge, Attitudes and Practices Regarding Community-Based Health Insurance in Dembecha Town, Ethiopia, 2014: A CrossSectional Design; 2015.

62. Atnafu DD, Tilahun H, Alemu YM. Community-based health insurance and healthcare service utilisation, North-West, Ethiopia: a comparative, cross-sectional study. BMJ Open 2018, 8(8):e019613. DOI: 10.1136/bmjopen-2017-019613.

63. Mebratie AD, Sparrow R, Yilma Z, Abebaw D, Alemu G, Bedi A. Impact of Ethiopian pilot community-based health insurance scheme on health-care utilisation: a household panel data analysis. The Lancet 2013, 381:S92.

64. Mebratie AD, Sparrow R, Yilma Z, Alemu G, Bedi AS. Dropping out of Ethiopia's community-based health insurance scheme. Health Policy Plan 2015, 30(10):1296-1306. DOI: 10.1093/heapol/czu142.

65. Shigute Z, Strupat C, Burchi F, Alemu G, Bedi AS. The Joint Effects of a Health Insurance and a Public Works Scheme in Rural Ethiopia. In: IZA Discussion Papers. Institute for the Study of Labor (IZA); 2017.

66. Shigute Z, Strupat C, Burchi F, Alemu G, Bedi AS. Linking Social Protection Schemes: The Joint Effects of a Public Works and a Health Insurance Programme in Ethiopia. J Dev Stud 2019, 0(0):1-18. DOI: 10.1080/00220388.2018.1563682.

67. Willingness of Community to Enroll in Community Based Health Insurance and Associated Factors at House Hold Level in Siraro District, West Arsi Zone, Ethiopia. JPHE 2019

\section{Figures}




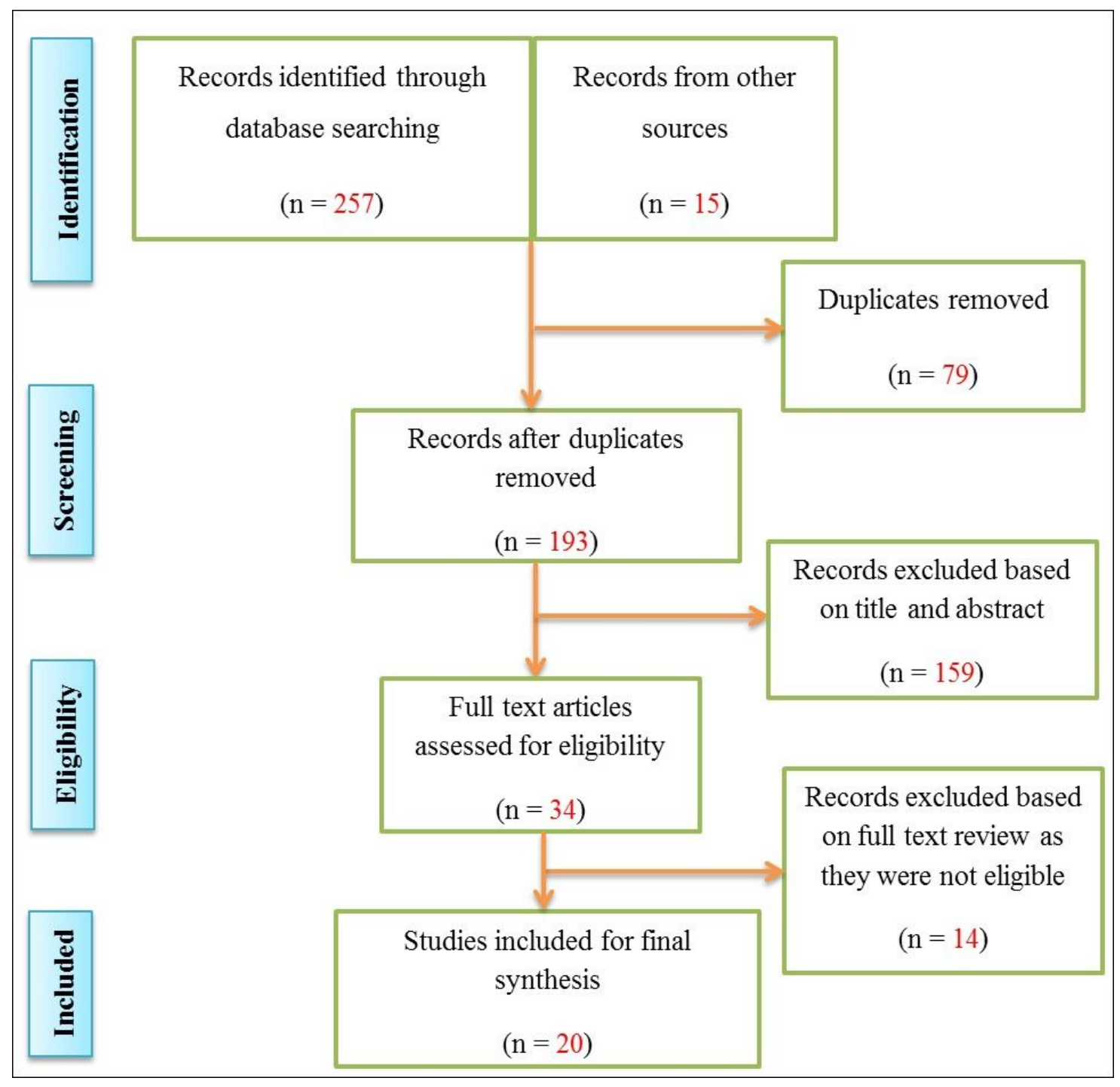

Figure 1

Flow diagram of literature screening strategy. 


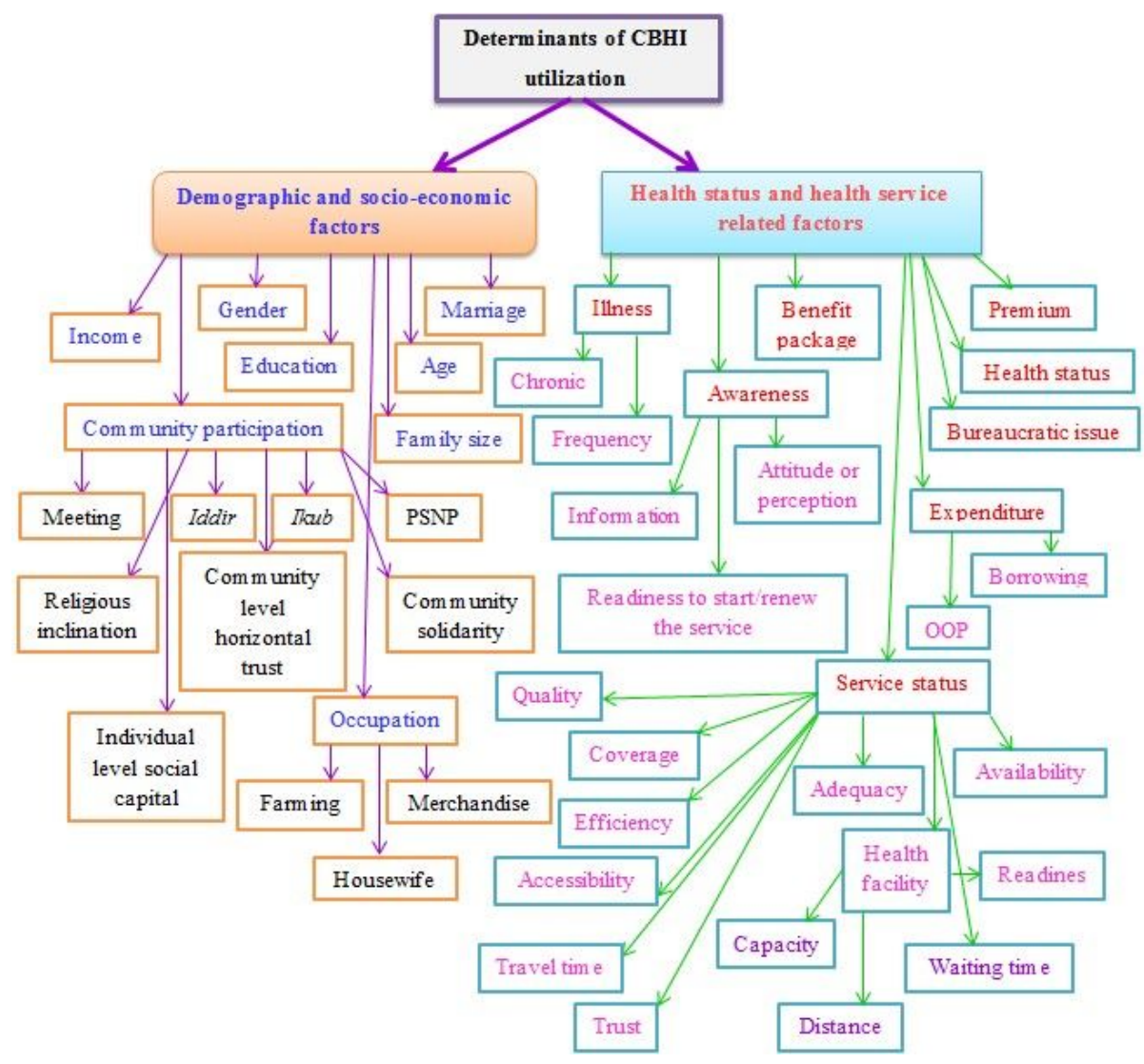

Figure 2

Thematic classification of the factors affecting $\mathrm{CBHI}$ in Ethiopia.

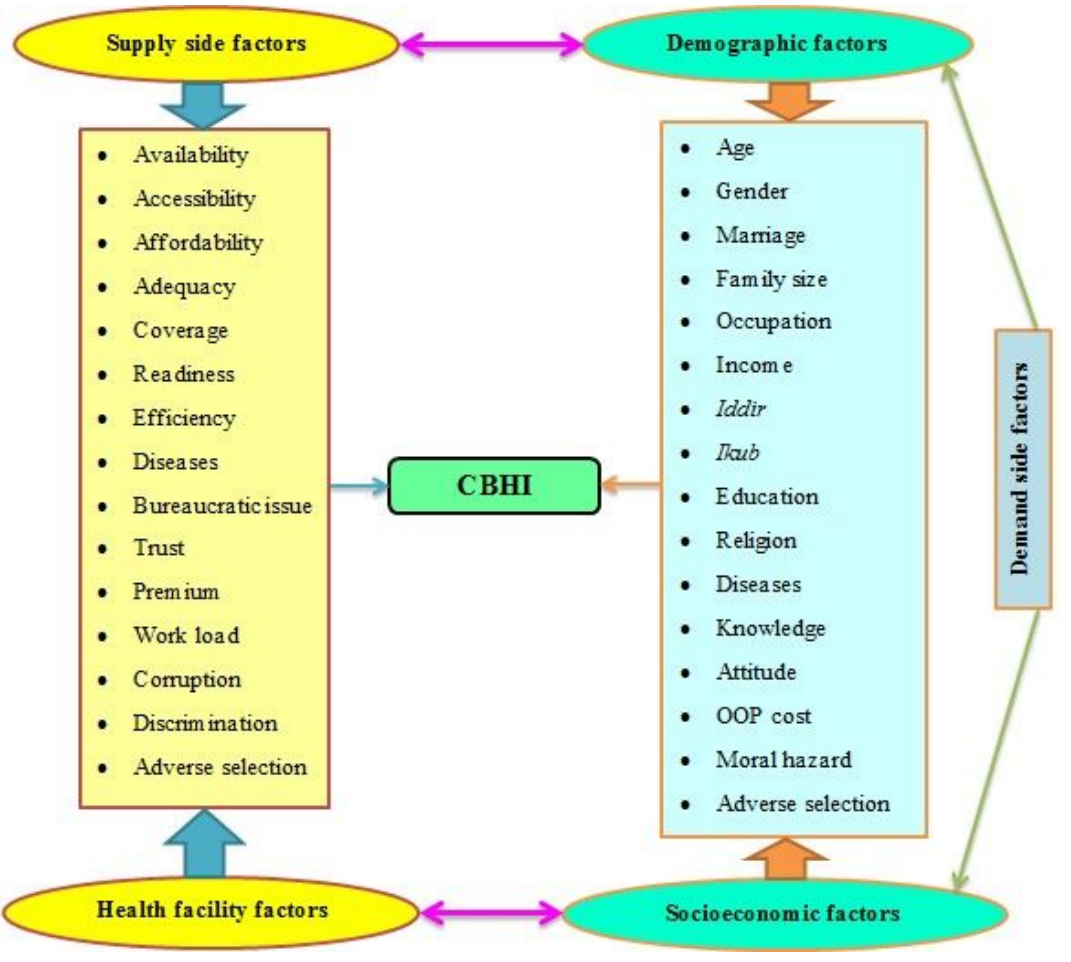

Figure 3

Summary of the determinants of $\mathrm{CBHI}$ in Ethiopia.

Supplementary Files 
This is a list of supplementary files associated with this preprint. Click to download.

- Riskofbiasassessmenttool.docx

- PRISMAchecklist.doc

- Summaryofdataextractionfromtheincludedstudies.docx 